\title{
VIEWS OF SCIENCE AND THEIR IMPLICATIONS FOR MUSLIM HIGHER EDUCATION
}

\author{
Eric Winkel*
}

\begin{abstract}
In this article, the author argues against the story of modernity as inevitable, irreversible, and teleological. He challenges this view by attempting to demonstrate the integrity of sciences and technologies. According to his view, perhaps unexpected, the pre-modern notion that the human being is the centre of the universe is inextricable from universal humility and a complete dependence on the divine. He concludes by stating that Muslim educators and administrators of higher education especially would do well to bear this perspective in mind when designing curricula for science courses. In order to achieve this, they would be well advised to aim at a re-reading of relevant qur'ānic passages and other sources of the classical Islamic heritage through the lens of its great exponents.
\end{abstract}

\section{The Three Views}

In his article "Three Views of Science in the Islamic World", ${ }^{1}$ Ibrahim Kalin classifies three worldviews associated with science among Muslims today.

The first view came into focus with the advent of modernity, specifically in the desire among intellectuals and elites to confront colonialisation, globalisation, and the pervasive dominance of the West. Since the weapon of the dominator, the master, was science and technology, it was only natural for the slave to seek that weapon for himself.

The second view takes Kuhn and Feyerabend and an awareness of the sociology of science to focus on the link between scientific activity and political economy. This view enjoys dethroning the "noble" pursuit of science by exposing its connection to crass realities of politics and economics.

A third view is neither modern, as the first is, or postmodern, as the second is. It instead turns the eye to a very different, now almost quaint, view of science as the study of our place in the universe.

The first view is pervasive in the Muslim world and may be called postcolonialisation: the continuation of the colonial experience through other means. The colonialist must project superiority. One projection of superiority occurred with the hunt, as in big game- or fox-hunting. "The hunters were extremely conscious of their

* Eric Winkel is an independent scholar, based in New Mexico, United States. He was a Principal Research Fellow with IAIS Malaysia until April 2012. 
role as rulers. The hunt becomes a means of reiterating racial superiority especially in the wake of 1857." 2 The spectacle of the hunt served to explain why in this case the British were seen as the legitimate rulers of India. The process of making the land a heroic setting in the spectacle of the hunt "not only renders the land a site of conquest and triumph," but also alienates it from "its primary users: the tribals and the natives." One way to discern how the spectacle functioned is to examine any glitches in the show. In Isabel Savory's "A Sportswoman in India," a mem sahib misses a shot, and the attendant shikari gives her a pitying glance. "Savory's writing underscores the fact that the failure was unacceptable because it had been in the presence of a native. The spectacle of the hunt, which serves to emphasise British supremacy, had collapsed in full view of the native it was supposed to impress." 4 This problem of spectacle gone wrong appears in George Orwell's essay about his experience in Burma, "Shooting an Elephant." He picks up his gun to investigate the report of a "mad" elephant and soon realises that the thousands of natives gathering around him and the now quite passive, peaceful elephant, have made it inevitable that he must kill it. He writes that he "perceived in this moment that when the white man turns tyrant it is his own freedom he destroys." The essay reveals imperialism to be a system where one must forego one's humanity to maintain the posture of superiority over a fellow human being.

The colonialist must continually perform his public role of superiority while aware that there is no physical or real difference between him and his subjects. He, and his society, draw up elaborate explanations for why they are rightfully dominant. In contemporary society, billionaires who produce nothing are said to have earned some amount of money, using the same verb accurately applied to the wage-earner. If they deign to do so, they tell stories about their superior leadership skills and business acumen in order to prove that they are rightfully esteemed. ${ }^{6}$

Here we are in the realm of "Extremistan," to use Nicolas Nassim Taleb's phrase from Black Swan. Here are some of the discoveries the 99 percent are making today about the 1 percent. For India, we may ask, Are we to assume that the handful of people who own one quarter of the wealth of India, who are billions of times wealthier than everyone else, are billions of times smarter or superior to everyone else? Does a superstar basketball player jump a million times higher than an amateur? Is a superstar singer a million times more talented? The same process of "explaining" superiority takes place in gender politics as well — men make stories to explain why they are dominant and women are subservient. ${ }^{7}$ For the West, the stories are those called the Grand Narratives of Modernity. Europeans and Americans are not dominant because they are more rapacious and violent and greedy - and "lucky": no, they are on top because they have separated religion from politics, or tapped into the steady progress of Science and Technology, or changed their pre-modern ways to become modern and punctual and efficient. The slave absorbs these narratives, and because 
the moments of confrontation are poignant and important, he takes the narratives very seriously. Here, post-colonialisation is the continuation of colonialisation by self-imposed assumptions.

The narrative or story of Modernity is that it is inevitable, irreversible, and teleological - ever upwards. In the first view we find the Muslim modernists of the nineteenth and twentieth centuries challenging a part of the grand narrative. From figures such as Muhammad 'Alī Pasha, Taha Hussein, Said Nursi, Sayyid Quṭb, representing the mixture we have had for a century of modernity and fundamentalism, the narrative is broken into two different stories: one is science and technology, and the other is religion and culture and the humanities. We want the master's weapon, Muslims of the first view say, but we don't want his culture.

In this same period, two groups of Muslims were cast as obstacles to the modernistfundamentalist quest. The first were the traditional ' $u l a m \bar{a}$ ' whose textuality and educational methods were seen as backward, irrational, and an obstacle to progress. A kind of Protestant revolution occurred where centuries of tafsìr literature could be discarded for an individual reading of the Qur'ān and Sunnah. Of course, any reading of a text takes place within a context, and by discarding the traditional context, the modernist-fundamentalist freed the text, only to alter it now to fit his own cultural baggage, which he acquired from the grand narrative of modernity. Take this text read by centuries of scholars the same way:

God does not change what is with a people of good-fortune and well-being until they change themselves. ${ }^{8}$

Here al-Alūsī, as is the tradition, elaborates that a people having good-fortune and well-being will not lose that until they change themselves by leaving good behaviours. The scholars also tied the verse to historical situations in an effort to find the exact "prompt" that revealed the verse. But suddenly in the twentieth century, and today, this verse is reversed and picks up the baggage of the Grand Narrative. This verse now is read by modernists and fundamentalists as being directed to contemporary Muslim societies in bad shape. It is used to blame Muslims for their situation: God will not change your bad fortune until you change yourself, and become modern. The master, in this case, succeeds in getting his slave to accept his subservience as being deserved and merited, because his god won't save him unless he changes himself leaves backwardness and becomes efficient, punctual, industrious, and scientific. The master succeeds in setting the stage for the post-colonialised to discard centuries of his own religious traditions. ${ }^{9}$

The second group were the Sufis, many of whom could also be described as being in the first group. They pushed for resistance to the West, whether violent or nonviolent (as with Bacha Khan, the "Frontier Gandhi"). A theme in this group is the jihād of the self, where one continuously examines the intent of the self-is it to 
submission to God, or is it toward selfish ends? This group focuses on the masterslave dynamic we have considered, partly through the awareness of accountability in the other world (äkhirah), which puts into stark light the true intentions of the self.

To the modernist-fundamentalist, these two groups were obstacles to progress, and they were, and are, criticised for their irrationality, textuality (and rote learning), and preoccupation with the other world. However, we may in turn challenge the modernist-fundamentalist with the other two views of science. The first challenge comes from a lack of understanding by the former of the sociology of science, the embeddedness of science in political economies. The second challenge comes from the third view, that by effacing tradition the former view leaves what was Islamic science open to misappropriation by forces of domination and aggression.

We may also challenge the former view by demonstrating the integrity of sciences and technologies. The naïve modernist-fundamentalist view assumes that transportation is transportation, for example, and that a car is a quantitativelyenhanced camel. A weapon is a weapon, for example, and money is money, and travel is travel. With this naiveté, they abrogate the traditional distance at which a traveller is defined as musäfir and no longer obligated with fasting that day in the month of Ramadan, for example. Instead of following the prophetic model, they instead arrogate to themselves the ability to interpret the body of law around travelling and fasting, by saying that travelling a distance today is easier than the same distance in the past, and therefore the law of travelling and fasting must change. This arrogation is similar to the battiniyyah heresy, which could posit that since zakāt means purity, one need not expend wealth in charity, but merely be pure. Taking the example of money, the idea is that the money we have today in a global capitalist system is the same as money then. The fact that money today is based on fiat currency and fractional reserves, and therefore is interest-based and usurious, escapes them. The idea that usury (interest) is acceptable is one that took hold historically only recently in earlier centuries Christianity, early Judaism, along with Islam, condemned usury, the charging of interest.

As for weapons, the explicit description of the tafsīr literature is that the qur'ānic verse mentioning "utmost power" referred to the bow. This understanding is effaced and replaced with "any" power including nuclear weapons. Weapons of mass destruction cannot be used without involving forbidden activities such as killing non-combatants, and as such cannot be lawful. When the traditional commentators interpret the qur'ānic verse "Fight them with what you are able to of power (8:60), they add the Prophet's commentary, "Yes, power is the bow," which he said three times. They also say that the bow is not the only power, and as such the commentary is linguistically similar to statements such as hajj is ${ }^{c}$ Arafät and tawbah is remorse. When there are other than simple weapons to be included, the commentators still provide the context for the weapon: the verse and the commentary might tell us 
that weapons besides the bow are used to dispel injustice, for example, and Caliph "Umar's statement may be included, that the Muslims should "fight" their enemies with pious deeds, charity, and the like. These cases consider a weapon in context, as an integral technology. That is, the intent and usage of the weapon cannot be removed from the physical weapon itself.

The insight into the integrity of technology shows us that the car is not a herd of camels. The autombile is a mechanical vehicle, an integral part of a car system or car culture, not a biological creature of the Earth. It should be obvious, but the naiveté of the modernist-fundamentalist view is pervasive, that technology and science are not neutral. The car we picture in our minds comes with oil that is extracted and refined and distributed, with asphalt and roads, with road rage and drunk driving, with pollution and toxicity. You can't have this car without polluting the rivers in the Niger delta, and paying corporations to drill underwater wells that spew oil unchecked into the Gulf of Mexico. The modernist-fundamentalist desire is for the science and technology of the West without its cultural artefacts. But the integral fact is that the car comes with all its undesirable properties, together with its speed and its effects upon society. Ivan Illich and others who studied car culture in the 1960s looked at the time people spent on driving their car and paying for it. They looked at the societal level as well, looking at commute times, infrastructure costs, and so on. In both the individual and societal cases, the actual speed of the car is 5.6 miles per hour. ${ }^{10}$ For example, a typical individual may commute 21 kilometres over 1.5 hours, working 1.5 hours for the monthly payment and operating costs. The speed of this car is $21 \mathrm{~km} / 3$ hours or $7 \mathrm{~km} / \mathrm{hr}$. One has to wonder why societies, as they found, commit 28 percent of their total expenditure of wealth on moving as fast as societies have done for centuries on foot and camels and horses. ${ }^{11}$

The assumptions also proclaim that science is science. And yet the shift in focus is too dramatic to be ignored. As Etienne Klein says,

On a pack of cigarettes, it is not written that smoking displeases God or compromises the salvation of our souls, but that "smoking kills." The salvation of the soul, the great object of theological discourse, has little by little been effaced for the good of the health of the body, which is the object of scientific preoccupation. In this sense, we consider a society to be truly modern when the priest and the ideologue have given their place to the expert, that is to say, when scientific knowledge and its technological development or industry are taken to be the only acceptable basis for society's organisations and policies. ${ }^{12}$

From this perspective, the fundamentalist is fully modern.

An attempt to revive some aspects of these two traditional groups (e.g., ' $u l a m \bar{a}$, Sufis) against a modernist-fundamentalist view is found in the concept of tradition or perennial philosophy, associated by Ibrahim Kalin with René Guénon, Seyyed 
Hossein Nasr, Syed Muhammad Naquib al-Attas, Osman Bakar, Mahdi Golshani and Alparslan Açikgenç. Ibrahim Kalin lists five elements of the viewpoint they are opposing, which may be summarised as follows.

1. Secular view of the universe, no space for the divine

2. Mechanistic world-picture, machine, clock

3. Hegemony of rationalism and empiricism

4. Cartesian bifurcation, alienation of knowing subject from object of knowledge

5. Exploitation of natural environment as source of global power and domination.

All five elements are not always present today in scientific activity. But to say that there is the science of Islamic civilisation and the science of today, and the twain do not meet, is not completely true either.

Let us consider the following analogy. We agree that soccer (football) is a game with a ball, two teams, a pitch, a time period, scoring, and rules. Rather than those elements being all together at one time, although they might be, what we see very often is a ball being kicked around. Sometimes the players divide themselves into two teams. Sometimes they count scores but don't have a time period; sometimes they use some rules but not others. Following a soccer ball in its lifetime, we might see all of these configurations, and even a moment when almost every element is present.

With this analogy, we may follow the ball of scientific activity. We find the ball being used mostly in crass and harmful ways. But occasionally the ball will be in a situation where the mechanistic world-picture is missing, and where the subject and object are seen integrally, and perhaps a result will emerge that is not a source of power and domination. These situations are moments for engagement. It might be helpful to consider contemporary scientific activity in that way. We will examine kinds of scientific activity that while not completely "soccer" in the Islamic civilisational sense, nevertheless indicate that something more is occurring than a ball being kicked around.

\section{Cartesian Bifurcation}

When Descartes decided that his thinking process (cogito) was his very being, he provided the sword which cultures and civilisations loosely called Western would use to alienate themselves from their bodies, their play, their neighbours, their fellow human beings, their fellow living beings, and their environment. This alienating split between subject and object is known as "Cartesian bifurcation." The Romantic movement attempted to counter this alienation, and writings within Western cultures have continuously questioned this sword cut and bemoaned its consequences. It is therefore distressing to find in the Muslim world and among many of its Islamic discursive spokesmen support for and engagement with the Cartesian bifurcation. It is 
Alfred Crosby's idea that the mentalité of the thirteenth-century Europeans concerned with measurement and quantification propelled them into a world-dominating science and technology. ${ }^{13}$ The ability to abstract and bifurcate gives power, but it loses the appreciation of quality (e.g., the Romantic movement).

The science carved out by the bifurcating cut may actually have been "hoist with his owne petar." This science first overturned Christian cosmology by introducing heliocentrism, but as Caner Dagli remarks, "[F]rom the point of view of relativity it is nonsense to say that the earth 'goes round' the sun." And so "the paradigm shift ushered in by such figures as Einstein, Max Planck, and Niels Bohr is important because it destroyed the destroyer." 14 And by putting all its eggs in the basket of measurement and physical realism, science was vulnerable to discoveries from a world that is measurable but imperceptible. The ability to predict the behaviour of the physical world on small and large scales, making this

the most successful scientific theory to date - paradoxically serves to undercut the assumption that the only real knowledge we can have of things is through scientific measurement. What we are measuring are things we can never perceive without a measurement. ${ }^{15}$

We hold a ball in our hand and the scientist says the only real knowledge we have of it is the measurements we make of it, and that our experience of it is "merely subjective or even meaningless from the point of view of science."16 But now we turn our attention to an electron or particle that "no one has, can, or ever will experience." 17 We now have measurements of remarkable precision of these particles, but since we cannot hold them in our hand, we have no experience of them. If the measurements are going to "mean" something, they have to be brought into our ordinary experience of the world. And so, "the new physics paradoxically undercuts classical bifurcation because it leaves us with the troubling proposition that our true scientific knowledge depends for its very survival upon the offices of our subjective, non-scientific experience." ${ }^{\prime 18}$ And since "quantum entities are wholly unlike ordinary entities, [...] rigid bifurcation into a subjective world of quality and an objective world of quantity" 19 is rendered all the more absurd.

The Cartesian bifurcation self-destructs at the micro level, where the objective measurements can only be interpreted subjectively, because there is no human scale experience of an electron. It also self-destructs at the macro level, because bifurcation implies an object that is external to us, and so when applied to the whole universe, we are left with the question, how do you measure as an external object something in which you are. Julian Barbour and Lee Smolin write,

As long as the domain in which the theory is actually compared to experiment involves only a portion of the universe there is no problem with the use of these external 
elements. However, when we enlarge our ambition and attempt to construct a theory that could apply to the whole universe, we should not be surprised to discover difficulties arising because the familiar structures that previously were defined in terms of things external to the system now have nothing to refer to. This is the origin of the criticisms of Newtonian mechanics known as Mach's principle and also of many of the difficulties, both interpretational and technical, in the study of quantum cosmology. ${ }^{20}$

The idea that there is an object external to us is "background dependent", which means, the idea depends on a background against which things happen. With the destruction of bifurcation comes the end of background dependence: we are then looking for theories that are background independent. Theories that are independent, that work without reference to backgrounds, focus on relations. And this is where Leibniz enters, because his calculus and physics depend on how things are related to each other, not independent of each other, and so "we" are able to fit into the equation. Leibniz criticised the bifurcation of measurement and perception, saying, "The Cartesians have lapsed here, as they count as nothing perception." 21

Voltaire's caricature of Leibniz in Candide, Pangloss, portrays him as ineffective, yet perhaps the inefficacy of its concept is not its disproof. Smolin writes,

But it took physics a long time to catch up to Leibniz's thinking. Even if philosophers were convinced that Leibniz had the better argument, Newton's view was easier to develop, and took off, whereby Leibniz's remained philosophy. This is easy to understand: a physics where space and time are absolute can be developed one particle at a time, while a relational view requires that the properties of any one particle are determined self-consistently by the whole universe..$^{22}$

The idea of absolute space and time is based on simultaneity, that there is an external clock that can be used to keep track of where and when things are. The idea of simultaneity depends on an objective universe gridded by Cartesian coordinates. Roger Penrose describes it this way. The very moment he is "typing this in my office at home in Oxford, is 'the very same time' as some event taking place on the Andromeda galaxy." ${ }^{23}$ The problem with this concept is,

There is no background space - a "screen" - which remains fixed as time evolves. We cannot meaningfully say that a particular point $p$ in space (say, the point of the exclamation mark on the keyboard of my laptop) is, or is not, the same point in space as it was a minute ago. ${ }^{24}$

From this, we must conclude that there is no meaning to be attached to the notion that any particular point in space a minute from now is to be judged as the same point in space as the one that I have chosen. While physicists agree with this description of measurement, as we have seen, the "what" it means cannot be objective or given, 
or even obvious. Instead, we have to ask about the phenomenological ramifications of a space and time that are not absolute. For Ibn al- ${ }^{\mathrm{c} A r a b i ̄ ~(d . ~ 1240), ~}{ }^{25}$ the phenomenological consequences of relative space and time is confusion. We consider below a relational description of non-absolute time and space from Ibn al- ${ }^{\mathrm{c}} \mathrm{Arabi} \mathbf{1}^{26}$

The forms of the universe which come out of these treasure troves appear to you; and you see them yourself.

You get knowledge of them and come to know about the universe what the universe does not know about itself, because of the force of piece-by-piece.

You are told, Everything that remains in the treasure troves, which never end, is like what you know. Who encompasses knowledge of one thing of a kind encompasses knowledge of the kind, because there is nothing subsequently but likes.

The two arcs of the circle come to meet until they make a circumference.

The circumference indicates the point in the circle.

The lines are made from the point to the circumference, and they do not transgress it.

The end of the line is at a point on the circumference.

It ends at the like of what it exited.

So the form of its first is the form itself of its last.

It induces, from the force of its last point which it ended upon on the circumference, a centre toward another circumference.

Half of it inside the first circumference and half of it outside, making the force of outward and inward.

The two arcs meet too as with the meeting of the first circumferal arcs until they become in its fashion/form, because it is impossible that it could exit in any but its form.

Then there arises by dint of the circumference what arose in the first circumference, on and on to no end; it is what protrudes from these treasure troves which have no end to what is contained therein. It is the new creation which is in existence ever-lastingly, and some people, or most people, are in confusion about that, as He said, Rather, they are in confusion about the new creation ${ }^{27}$ with every breath, but in the fashion we mentioned. So the points are the reason for the presence of the circumference and the circumference is the reason for the arrival of knowledge about the points. Therefore, the circumference is Divine and Creation, and the points are Divine and Creation, and these two forces flow through every circle, arising from the first circle.

So as the circles arise, however many there are, and they keep arising, until the first of these circles which happened becomes hidden, unrecognisable, imperceptible, because each circle made near to it or distanced from it is in its form/image.

The phenomenological consequence of the universe, of physical space, appearing and disappearing is seeming confusion. Penrose says,

It may seem alarming that our very notion of physical space seems to be of something 
that evaporates completely as one moment passes, and reappears as a completely different space as the next moment arrives! ${ }^{28}$

The above passage from Ibn al- ${ }^{\mathrm{c}}$ Arabī is a key text for him, and the feeling of confusion is answered, in a sense, by the body of Prophetic practice. In other words, instead of nihilism, for example, Prophetic practice is how we deal with our confusion about an ever-changing world. Also, Ibn al- ${ }^{\mathrm{c}}$ Arabī is clear that there is something special about the human faculty to perceive the universe, which is part of a long, perennial tradition, where the complete human being (al-insān al-kāmil) is more poised to understand the universe than the universe itself. Caner Dagli speaks of it this way:

This is why man can know the whole of the world, for everything therein is an unfolding and limitation of qualities he possesses in himself in a total way. ${ }^{29}$

Perhaps therefore, as unexpected as it may be in light of the certainties of Newtonian science, the pre-modern notion that the human being is the centre of the universe is inextricably connected with universal humility and a complete dependence on the Divine. It is only when Man alienated himself from his Mother (Earth) that the hubris of worldly domination and subjugation of all other beings came about.

But it seemed so magisterial to be heliocentric, to gaze at the universe from the position of standing on the Sun! And yet we do not stand on the Sun, as Seyyed Hossein Nasr points out, we stand on the Earth; ${ }^{30}$ and so we should have a geocentric perspective. The hoisted science cannot tell us where we stand. As with postmodernism, no place is privileged. Let us take this seriously: no place is objectively the centre, no background is privileged; there is no Cartesian grid on the universe with a 0,0 point. If there were a centre, it would be a "place" we have no access to, in the same way that if there are little electrons, they are out of our sphere of perception and experience. When we arrive at this postmodern perspective, we are able to move to a position we may call post-postmodern or pre-modern: we stand on the Earth, therefore the Earth is our centre with respect to the universe. We measure things in comparison to our bodies (finger and arm lengths, positioning, strides). We understand things geo-metrically (etymologically, the measure of the Earth); we understand distances and angles and shapes. So we are ready to move on and reject the bifurcation of subjective and objective.

The rigid bifurcation trips the scientist who tries to link the two worlds of measurements-of-the-unseen and experience-of-the-seen. Here are electrons and particles we can measure with clicks on a counter. We might think measurements are objective and experiences subjective. Everything comes to us through our individual senses. We might think that the results of measurements can be extrapolated to tell us something objective in the world of the experience-of-the-seen. But the data is one thing and the interpretation another. As Caner Dagli puts it, "The 'collapse' of the 
state vector is still debated by physicists as a matter of philosophy, since there is no general disagreement about the data." ${ }^{\prime 1}$ Further,

The problem with superstring theory, hidden variable theory, many-universe theory, is that they are all mathematical models based upon the exact same body of data, and they all predict the data equally well. These models are sometimes so wildly different that any pretense to some one great scientific conception of the universe must be seen as philosophical hubris. ${ }^{32}$

As we will consider in the last section, the "collapse of the state vector" is a formalism, a mathematical description. The math describes what happens, but it will be another language (e.g., English, French) that provides the interpretation. The majority of physicists support the Copenhagen interpretation of quantum mechanics, to the extent they are concerned with interpretation. In Caner Dagli's phrase, they generally do avoid philosophical hubris. The same cannot be said about other intellectuals peering into physics from the outside. Christopher Norris is intent on challenging the postmodern philosophy that gives itself authority by reference to physics. Its practitioners take for granted, he says, the "idea that their position [anti-realist and cultural-relativist] finds support from the latest findings of theoretical physics." $\mathrm{He}$ continues:

Typical of these is Jean-François Lyotard's strangely placid assurance that 'postmodern' science has nothing do with truth - even truth at the end of enquiry - but everything to do with uncertainty, undecidability, chaos, paralogistic reasoning, the limits of precise measurement, and the observer-dependent nature of (so-called) physical 'reality'. ${ }^{33}$

In this present work, the reader will find our arguments meeting many strange bedfellows. Postmodernity, with its uncertainty and relativism, is welcomed for its rejection of the bifurcated Cartesian heritage. However, it in turn is rejected in favour of physicists who are interested in finding realism, such as Julian Barbour, Roger Penrose, Anton Zeilinger, and David Bohm. It is possible for philosopherscientists to reject the bifurcation of objective and subjective and move, not to chaos but to the order in complexity, and to reject both my reality and no reality for shared reality. Where John Locke defined consciousness as "the perception of what passes in a man's own mind," 34 we might more fruitfully return to the sixteenth-century Latin etymology of consciousness, the knowing (sci-) with (con) others. Even in unconventional studies of consciousness, the prevailing idea is of a solipsistic consciousness; one critic decries

the neuroscience camp, who mainly think that people are self-sufficient computing machines, and on the other you have the phenomenologists and Buddhists, who also think consciousness is private [...] who believe they can discover "pure consciousness" 
without third-person reflectivity. You must have noticed that when any one talks about "pure this" or "pure that" they are always men, or women talking men's language..$^{35}$

If measurement does not provide objective truth but instead exists with its experiential interpretation, we return to our geo-centrism, our own position. As H. D. Thoreau remarked, somewhat tongue-in-cheek,

In most books, the I, or first person, is omitted; in this it will be retained; that, in respect to egotism, is the main difference. We commonly do not remember that it is, after all, always the first person that is speaking. I should not talk so much about myself if there were anybody else whom I knew as well. Unfortunately, I am confined to this theme by the narrowness of my experience. Moreover, I, on my side, require of every writer, first or last, a simple and sincere account of his own life, and not merely what he has heard of other men's lives; some such account as he would send to his kindred from a distant land; for if he has lived sincerely, it must have been in a distant land to me. ${ }^{36}$

In this call for the first-person, we may see a confrontation with the expert, who derives his authority from abstraction and objectification. We may see in Thoreau's wallowing in the earthy, the real, the bodily, a Romantic rejection of Cartesian bifurcation. Thoreau has an instantly recognisable style. One may ask whether he had to refashion a language that had become overly subject to bifurcation. In Arabic, perhaps in contrast, the subject-object bifurcation is grammatically unnatural. We in the modern English speaking world are distant from a Sufi worldview and Arabic language that do not support bifurcation. Samer Akkach says,

When dealing with the Sufi conceptions of reality, physical or metaphysical, it is important to recognise the essential difference between their approach and the Cartesian view that conditions our modern understanding. Sufis do not see the world through the Cartesian polarity of subject and object, mind and extension, conscious soul and extended bodies. In fact the subject-object polarity finds neither linguistic nor conceptual support in Arabic. ${ }^{37}$

Not only is this a worldview that has a non-Cartesian perspective, but the language itself does not support the subject-object polarity central to the Cartesian coordinates. Thinking, in Arabic, could never be equated to "I am".

There are many reasons why science has been sidetracked onto the Cartesian line, supported by sociology, economics, and politics. There is also a psychological explanation - it appeals to the masculine self who wants to predict and control wild, fecund, feminine Mother Nature. Steven M. Rosen identifies the Cartesian coordinate system as a doomed way to banish chaos, where "chaos" and the ancient Greek concept of the unbounded (apeiron) is connected with Mother Nature. This is the line of science that wants to control nature. It perhaps springs from the masculine 
attempt to order and regulate the feminine. Rosen says the masculine claim of objectivity, against feminine subjectivity, is found when the "I" or "eye" is put at 0,0 and proceeds to make everything an object, all the while pretending that "I" am separate from this objectified object. But then in modern physics the problem of the speed of light arose, where the classical space (of absolute time and absolute space) "no longer could be taken a priori as a changeless medium." Rosen shows that the "solution" to this problem was to empiricise "three-dimensional space, treating it, in effect, as a variable object in a new, more abstract four-dimensional medium." 38

The physicist David Finkelstein considers the same stages in terms of iconoclasm, where scientists have idols they need to destroy. From this perspective, Galileo destroys the idol of absolute time, where there is no space separate from time. From this stage, "we cannot recognise the same place at a different time." ${ }^{39}$ But there is still an absolute space. So the next idol bashing brings about relativity, where there is a fused spacetime, where not only is there no time without space, there is no space without time; and further, matter and spacetime are fused. But we still have an idol: the "state", with the belief is that the state is independent of the observer, and that there is a distinction between knowing a state and doing something to a state. We "no longer separate them but unite them in Heisenberg's one simple concept of operation without object." 40

Finally, the Cartesian universe is also largely visual. There is something about vision and the masculine, god-like notion of objectivity. Sound, in contrast, is suffuse, comes from all directions, is perceived differently, and most importantly, cannot be objectified. As with the sand mandala, swept away after its creation, when the auditory event is over, it can never be repeated. Samer Akkach explains that auditory space is not a pure or empty, boxed-in space but is an "essentially inhabited space." As a consequence, "This means that one cannot simply be independent of it; one cannot stand outside it and experience it but has to be within it in order for such space to exist. Acoustic space cannot be frozen in the matrix of matter; it cannot be preserved, as in a photographic form, and made to passively endure in the memory. For there is no way to preserve sound as sound; when sound stops, its opposite, silence, prevails. ${ }^{\prime 41}$

It is no accident that the audible Qur'ān is more prominent in lived Islam than the textual one. Kristina Nelson points out that Western scholars have typically emphasised the textual part of the Qur'ān. She calls such scholarship one-dimensional, and contrasts it with the auditory space that characterises the Qur'ān in Muslim society. She says

[t]hat the Qur'ān is central to Islamic society, that its significance is communicated by the sound as well as by the meaning and history of the revelation, and that most access to the Qur'ān is through the oral tradition explains to a great degree the suffusion of the sound throughout the fabric of society and the prestige and respect accorded to it. ${ }^{42}$ 


\section{Conclusion and Recommendations}

Reflecting on the trajectories sketched here, one central direction emerges which educators and administrators of higher education would do well to bear in mind when designing curricula for science courses.

- European science with its technological success has to be placed within an overarching context anchored in the two worlds of the Qur'ān: our consciousness of physical existence and corporeal phenomena, and the immaterial unquantifiable dimension of human experience.

- A re-reading of qur'ānic passages through the lens of great Islamic exponents will help expand the minds and hearts of students in the laboratory and classroom.

\section{Notes}

1. Muslimphilosophy.com, available online at http://www.muslimphilosophy.com/kalin/index.html (accessed on 17 May 2012).

2. Pramod K. Nayar, English Writing and India, 1600-1920: Colonizing Aesthetics (New York: Routledge, 2008), 167.

3. Ibid., 168.

4. Ibid.

5. George Orwell (1903-1950), "Shooting an Elephant," available online at http://www.onlineliterature.com/orwell/887/ (accessed on 17 May 2012).

6. The rich certainly are different. Let us try to graph the difference for the case of India. The "bottom" axis of our graph will be the circumference of the Earth, which is 4 billion centimeters $(4.01 \mathrm{x}$ $\left.10^{9}, 40,075 \mathrm{~km}\right)$. We'll put the population of $1.56 \times 10^{9}$ circling the equator of the Earth. Every one centimeter, there are 2.6 people. We will now glide over the population circling the equator easterly. Their height will be their wealth, at the scale of 1 dollar equaling $100^{\text {th }}$ of a millimeter. As we start our glide, we will go many kilometers over a population with negative wealth. Eventually, our glide will be over people with a dollar a day of wealth, which will put them (annually) at .365 of a millimeter in height. We will see this population height continue well around the globe. But then we will see the 50 million middle class Indians. Somewhere over Karachi, approaching India from the west, we now see a bump upward in the height of the population, the middle class. Their height is 10 centimeters. We are now seeing another bump, the millionaires. Five hundred meters from our starting place, we see the millionaires, at a height of 10 meters. We have glided for a long time around the equator, over a population with negative height and then a millimeter in height. Just at the end we saw heights of a few centimeters, And then ten meters. Now, 21.15 centimeters from our starting point, we find the billionaires. Suddenly the height goes from centimeters and a few meters to 10 kilometers. And in the end, there are a few centimeters of population with wealth at one hundred kilometers in height. These last few meters own one quarter of India's wealth.

7. My "Orwell" moment for this process with gender came while watching a building project in Pakistan. A scrawny person (of the stronger sex) squatting on a platform was laboriously piling adobe blocks one by one onto the head of a person (of the weaker sex). It seems that he could only manage to hold a single block at a time, while she was transporting eight blocks on her head across the field. 
8. Maḥmūd al-Alūsī al-Baghdādī, Rūḥ al-macānī (Beirut: Dār al-Kutub al-c'llmiyyah, 1996), 7:110, referring to Qur'ān 13:11.

9. It is through Western eyes that Muslim societies are seen as failures, perhaps. But using a criterion such as remembrance of the next world, with its opposite, ghaflah, a discourse could easily be constructed that shows Twitter and Facebook and the rest to be mindless distractions, not praiseworthy accomplishments.

10. Ivan Illich writes, "The model American male devotes more than 1,600 hours a year to his car. He sits in it while it goes and while it stands idling. He parks it and searches for it. He earns the money to put down on it and to meet the monthly instalments. He works to pay for gasoline, tolls, insurance, taxes, and tickets. He spends four of his sixteen waking hours on the road or gathering his resources for it. And this figure does not take into account the time consumed by other activities dictated by transport: time spent in hospitals, traffic courts, and garages; time spent watching automobile commercials or attending consumer education meetings to improve the quality of the next buy. The model American puts in 1,600 hours to get 7,500 miles: less than five miles per hour. In countries deprived of a transportation industry, people manage to do the same, walking wherever they want to go, and they allocate only 3 to 8 per cent of their society's time budget to traffic instead of 28 per cent. What distinguishes the traffic in rich countries from the traffic in poor countries is not more mileage per hour of life-time for the majority, but more hours of compulsory consumption of high doses of energy, packaged and unequally distributed by the transportation industry" (see http://evans-experientialism.freewebspace.com/illich02.htm, accessed on 17 May 2012).

11. For an exploration of these ideas with reference to Islamic civilisation, see my "Walking Away from Sustainability," a paper presented at the Philosophy of Sustainability conference, December 2010, Centre for Civilisational Dialogue (CCD), University of Malaya, Kuala Lumpur, to be published by CCD and UNESCO.

12. Etienne Klein, “Actes du seminaire international: La culture scientifique au Sud,” Marseilles, 29-30 September 2009, available online at http://www.latitudesciences.ird.fr/documents/actes_PCST.pdf (accessed on 21 May 2012), 6 (my translation).

13. See Alfred W. Crosby, The Measure of Reality: Quantification and Western Society, 1250-1600 (Cambridge: Cambridge University Press, 1997).

14. Caner Dagli, "The Time of Science and the Sufi Science of Time," available online at www. ibnarabisociety.org/articles/timeofscience.html (2005; accessed on 21 May 2012; the following quotes in this paragraph all come from this reference).

15. Ibid.

16. Ibid.

17. Ibid.

18. Ibid.

19. Ibid.

20. Julian Barbour and Lee Smolin, "Extremal Variety as the Foundation of a Cosmological Quantum Theory," available online at http://arxiv.org/abs/hep-th/9203041 (1992, accessed on 21 May 2012), 2.

21. Leibniz, Monadologi (Oviedo, Spain: Pentalfa, 1981), trilingual edition, intro. Gustavo Bueno, transl. Julian Velarde, available online at http://www.helicon.es/dig/8542205.pdf (accessed on 21 May 2012), 82.

22. Lee Smolin, "The Case for Background Independence," available online at http://arxiv.org/PS cache/hep-th/pdf/0507/0507235v1.pdf (2010, accessed on 21 May 2012), 8.

23. Roger Penrose, The Road to Reality: A Complete Guide to the Laws of the Universe (London: Jonathan Cape, 2004), 384.

24. Ibid., 385 . 
25. About the centrality of Ibn al- ${ }^{\mathrm{c}}$ Arabī here and in Islamic civilisation in general, consider Samer Akkach's statement: "While dealing with a range of Sufi texts, the works of Ibn al-cArabī - by virtue of their richness, comprehensiveness, and coherence - are taken to represent the Sufi worldview in its utmost maturity and complexity. In this I run the risk of obliterating differences and variations in Sufi thoughts and teachings and of overstating Ibn al- ${ }^{\mathrm{c} A r a b} \overline{1}^{\prime} \mathrm{s}$ centrality and influence in the Islamic tradition. I acknowledge, however, that Ibn al-'Arabī's idea did not emerge in a vacuum and that he absorbed and represented much of what earlier and contemporary Sufis had established. His pivotal position comes from the inspirational power, comprehensiveness, cogency, and profundity of his syntheses, which, as many studies have shown, were instrumental in perpetuating and universalizing Sufi ideas in a coherent way. Also, Sufi conceptions of the genesis, structure, and layout of the universe reveal a remarkably consistent core, with variations being traceable mainly in modes of expressions. Ibn al-'Arabī's monumental Futūhāt al-makkiyyah, the main focus of this study, is known to have served as a main reference on Sufi ontology and cosmology for subsequent generations" (Samer Akkach, Cosmology and Architecture in Premodern Islam: An Architectural Reading of Mystical Ideas (New York: SUNY, 2005), 25.

26. Ibn al-c'Arabī, Futūhāt al-makkiyyah, Bulaq edition, available online at http://www.archive.org/ details/alfutuhatalmakki03ibnauoft (accessed on 21 May 2012), Chapter 369, 3:403, lines 11-25.

27. Qur'ān 50:15.

28. Penrose, The Road, 385.

29. Caner Dagli, "On Beginning a New System of Islamic Philosophy," The Muslim World 94, no. 1 (January 2004), 19.

30. "The fact remains that we are not standing on the sun [...]. To look upon the vast vault of the heavens as if one lived on the sun creates a disequilibrium which cannot but result in the destruction of that very earth that modern man abstracted himself from in order to look upon the solar system from the vantage point of the sun in the absolute space of classical physics" (William C. Chittick (ed.), The Essential Seyyed Hossein Nasr (Bloomington IN: World Wisdom, 2007), 197).

31. Dagli, "On Beginning," 22.

32. Idem, "The Time,"

33. Christopher Norris, Quantum Theory and the Flight from Realism: Philosophical Responses to Quantum Mechanics (New York: Routledge, 2000), 2.

34. http://www.britannica.com/EBchecked/topic/133274/consciousness (accessed on 21 May 2012).

35. Tjiniman Murinbata and Charles Whitehead, "Why Consciousness Conferences Are not Really Getting Us Anywhere: A Stone-Age Anthropologist Explains," Journal of Consciousness Studies 7, no. 6 (2000), 82.

36. Henry David Thoreau, Walden (1854), Chapter One: "Economy," available online at http://www. literaturepage.com/read/walden-1.html (accessed on 21 May 2012).

37. Akkach, Cosmology, 55.

38. Steven M. Rosen, Dimensions of Apeiron: A Topological Phenomenology of Space, Time, and Individuation (Amsterdam and New York: Rodopi, 2004), 44.

39. David Finkelstein, "Emptiness and Relativity," in: B. Alan Wallace (ed.), Meeting at the Roots: Essays on Tibetan Buddhism and the Natural Sciences (Berkeley CA: University of California Press, 2001), 3.

40. Ibid., 7.

41. Akkach, Cosmology, 199.

42. Kristina Nelson, The Art of Reciting the Qur'an (Cairo: The American University of Cairo Press, 2001), 28. 